\title{
Contribution of Ultrasounography to Diagnosis and Fast Symptomatic Recovery: A Ganglion Cyst Causing Compression in the Neighborhood Ulnar Nerve
}

\author{
Banu Dilek ${ }^{\mathrm{a}, \mathrm{c}}$, Erhan Capkin ${ }^{\mathrm{b}}$, Murat Karkucak ${ }^{\mathrm{b}}$
}

\section{To the Editor}

A 43-year-old female was admitted with complaints of left volar wrist in swelling, pain and numbness in the fourth and fifth fingers. The patient had symptoms for 6 months without trauma. In physical examination, there was swelling in her ulnar side of the volar wrist and no limitation in wrist ROM. Muscle strength and sensory examination were normal with negative Tinel sign. In ultrasonography, there was a ganglion cyst (size $11 \times 5.6 \times 6 \mathrm{~mm}$ ) near the ulnar nerve in wrist (Fig. 1) with no Doppler sign (Fig. 2). After aspiration with ultrasound guide, the patient's symptoms (pain and numbness) were significant decreased (Figs. 3 and 4). Wrist pain of patient was evaluated with visual analog scale $(0-10 \mathrm{~cm})$ and was reduced from 9 to 3 after aspiration and then a splint was given to the patient.

Ganglion cyst is the most common soft tissue tumor of hand and most frequently arises adjacent to joints and tendons, but may also be intratendinous or intraosseous [1, 2]. It occurs most commonly on the dorsal side of the wrist (70\%), followed by volar side $(20 \%)$ of wrist and tendon sheath of fingers [3]. They are most common between the second and fourth decades of life. Treatment options include observation, aspiration, and surgical excision [4]. Ganglions of the wrist and hand causing compressive neuropathies are rare clinical entities. Ganglion cyst is rare in the neighborhood ulnar nerve at wrist and it may predispose to the development of neuropathy via compression [5]. Here is the ganglion cyst which was aspirated by ultrasound and after that, pain and numbness of the patient's wrist were relaxed. Ultrasonography has an important place in both diagnosis and fast treatment like this case. This technology offers several inherent advantages.

\section{Manuscript accepted for publication April 20, 2016}

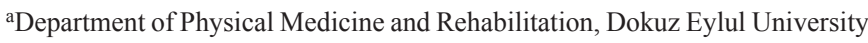
Faculty of Medicine, Izmir, Turkey

bepartment of Physical Medicine and Rehabilitation, Faculty of Medicine, Karadeniz Technical University, Trabzon, Turkey

${ }^{\mathrm{c} C}$ Corresponding Author: Banu Dilek, Department of Physical Medicine and Rehabilitation, Dokuz Eylul University Faculty of Medicine, Izmir, Turkey. Email: banu.dilek@deu.edu.tr

doi: http://dx.doi.org/10.14740/jnr374e

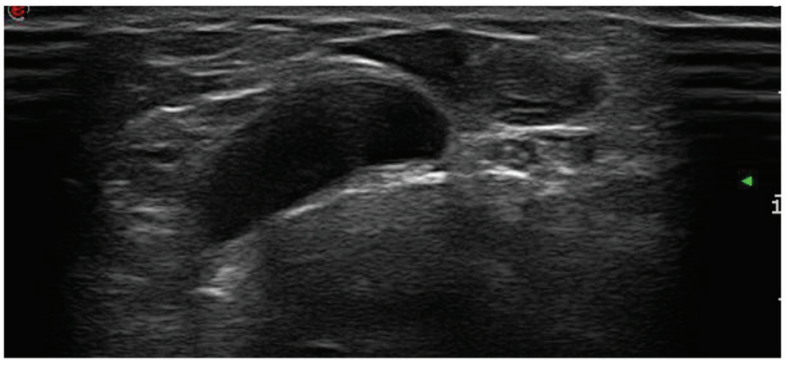

Figure 1. Ganglion cyst, unlar nerve.

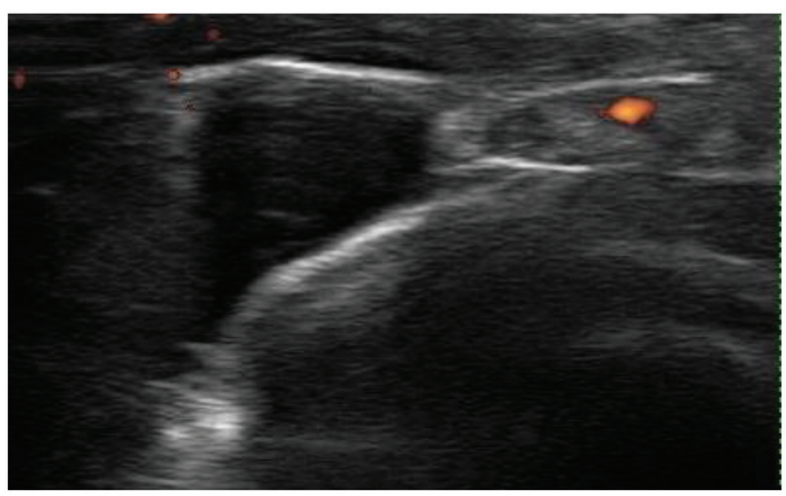

Figure 2. Ganglion cyst, unlar nerve and unlar artery.

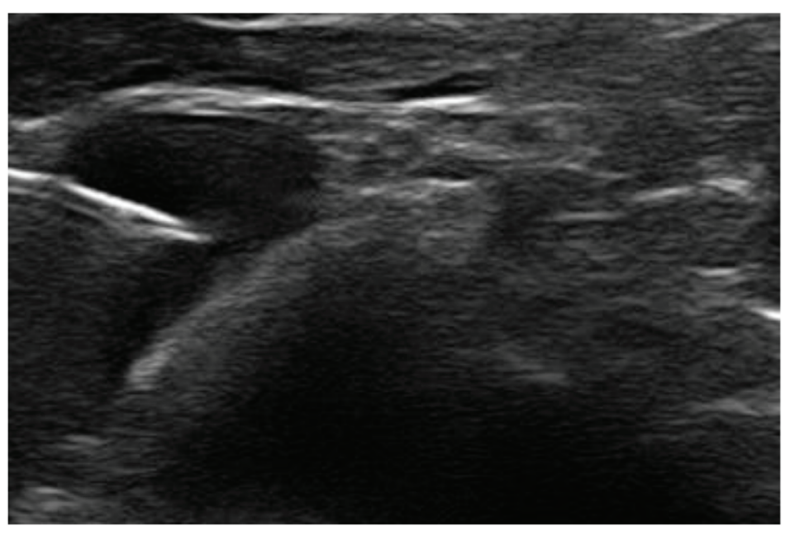

Figure 3. Aspiration of ganglion cyst with nedle via ultrasonography. 


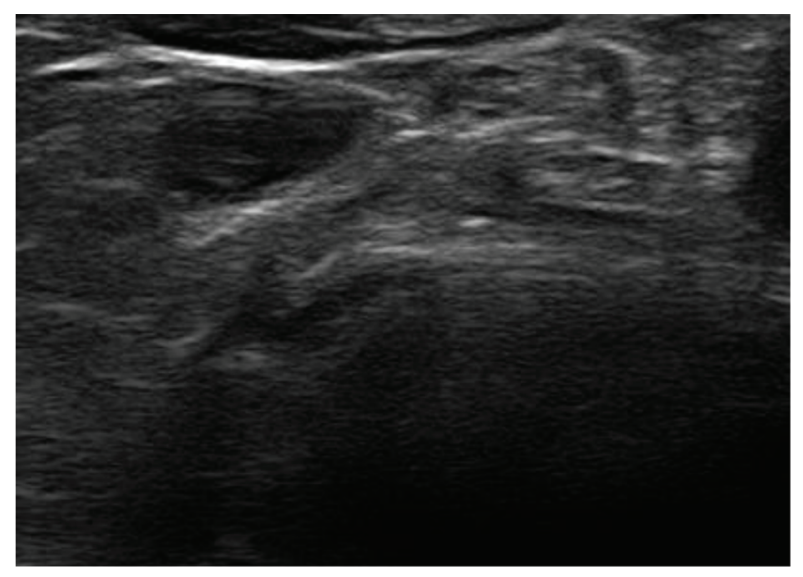

Figure 4. After aspiration.

Being non-invasive, with a quick scan time and without radiation make it well accepted by patients. There are several advantages from the clinician's point of view. The ability to visualize needles and target structures in real time makes it an ideal tool for the guidance procedures used in diagnosis and management [6].

\section{Conflicts of Interest}

None.

\section{References}

1. Meena S, Gupta A. Dorsal wrist ganglion: Current review of literature. J Clin Orthop Trauma. 2014;5(2):59-64.

2. Greendyke SD, Wilson M, Shepler TR. Anterior wrist ganglia from the scaphotrapezial joint. J Hand Surg Am. 1992;17(3):487-490.

3. Westbrook AP, Stephen AB, Oni J, Davis TR. Ganglia: the patient's perception. J Hand Surg Br. 2000;25(6):566567.

4. Thornburg LE. Ganglions of the hand and wrist. J Am Acad Orthop Surg. 1999;7(4):231-238.

5. Jayakumar P, Jayaram V, Nairn DS. Compressive neuropathies related to ganglions of the wrist and hand. Hand Surg. 2014;19(1):113-116.

6. del Cura JL. Ultrasound-guided therapeutic procedures in the musculoskeletal system. Curr Probl Diagn Radiol. 2008;37(5):203-218. 